\title{
Effect of maternal smoking in pregnancy and childhood on child and adolescent sleep outcomes to 21 years: a birth cohort study
}

Frances O'Callaghan ${ }^{1 *}$, Michael O'Callaghan², James G. Scott ${ }^{3}$, Jake Najman ${ }^{4,5}$ and Abdullah Al Mamun ${ }^{4}$

\begin{abstract}
Background: The effects of prenatal maternal smoking have been studied extensively, however little research has examined the effects of prenatal exposure to maternal smoking on offspring sleep, particularly over several developmental periods. We examined the effects of prenatal maternal smoking and postnatal smoking from birth to 14 years, on offspring sleep at 6 months, 5, 14 and 21 years.

Methods: This was a prospective, community-based birth cohort study involving 7223 women who delivered a singleton child in Brisbane, Australia between 1981 and 1983. Women were recruited at the first antenatal visit. Offspring sleep problems were reported by mothers at 6 months, 5 and 14 years, and by youth at 14 and 21 years. 3738 mothers prospectively reported their smoking status from pregnancy to 14 years postpartum. Youth snoring was reported by mothers at 14 years and by youth at 21 years. Multinomial logistic regression analyses were performed.

Results and discussion: Prenatal maternal smoking was independently associated with an increased risk of offspring adolescent parasomnias including walking and talking in sleep and nightmares, and an increased likelihood of being in the highest quintile for maternal and youth reported sleep problems at 14 years. Maternal postnatal smoking was associated with increased likelihood of offspring snoring at 14 years.

Conclusions: Exposure to maternal prenatal smoking has different effects on offspring sleep compared to exposure to postnatal smoking. Prenatal smoking exposure may be associated with changes in neurodevelopment whereas postnatal smoking is more likely to affect the respiratory system. These findings highlight the long lasting and potentially serious clinical effects of exposure to pre and postnatal maternal smoking on offspring, the mechanisms by which warrant further investigation.
\end{abstract}

Keywords: Sleep, Smoking, Pregnancy, Birth cohort, Childhood, Adolescence, Young adults

\section{Background}

Sleep is related to various aspects of mental, cognitive and physical wellbeing in children and adults [1]. There is abundant evidence of the adverse consequences of sleep problems on individuals including attention problems [2], neuropsychological problems [3], learning [4], emotional and behavioural problems $[5,6]$, daytime

\footnotetext{
* Correspondence: f.ocallaghan@griffith.edu.au

'School of Applied Psychology and Menzies Health Institute, Griffith

University, Gold Coast 4222, Australia

Full list of author information is available at the end of the article
}

functioning and quality of life [7, 8]. The effects of maternal smoking during pregnancy have also been studied extensively, with exposed children being at greater risk of a range of adverse outcomes [9-13], some evident even in adulthood, for example nicotine dependence [14] and adverse effects on intelligence [15]. More recently studies have suggested an association between prenatal maternal smoking and sleep problems in children [16-19]. If confirmed and the relationship persisted, this could potentially be an important mechanism

(c) The Author(s). 2019 Open Access This article is distributed under the terms of the Creative Commons Attribution 4.0 International License (http://creativecommons.org/licenses/by/4.0/), which permits unrestricted use, distribution, and reproduction in any medium, provided you give appropriate credit to the original author(s) and the source, provide a link to the Creative Commons license, and indicate if changes were made. The Creative Commons Public Domain Dedication waiver (http://creativecommons.org/publicdomain/zero/1.0/) applies to the data made available in this article, unless otherwise stated. 
contributing to adolescent and young adult sleep problems and their associated morbidity.

There are several mechanisms by which prenatal exposure to smoking may explain subsequent adverse outcomes for the child. These include direct effects of tobacco products, including nicotine, on the developing brain's acetylcholine neurotransmitter systems and cells involved in sleep regulation [20-22]; known effects on later child behaviour; and confounding by family and social factors. A recent review of epidemiological and animal studies concluded that the pathophysiology for this diverse spectrum of outcomes remains incompletely understood [23] though epigenetic processes may be influential [24].

Few studies, however, have examined the effects of prenatal exposure to smoking on offspring sleep. A polysomnographic study in preterm infants demonstrated disrupted sleep structure and continuity and increased movement in infants exposed to in utero maternal smoking [25]. Two recent studies have examined these associations longitudinally, both indicating that the effects are not explained by postnatal maternal smoking. In one of these studies, prenatal nicotine exposure in a sample of 139 children was associated with sleep problems to 9 years [26]. A second study of low SES, high-risk mothers recruited after delivery found a dose-response relationship between prenatal tobacco exposure and persisting sleep problems in 808 children from 1 month to 12 years [27]. These studies provide valuable information and raise two important questions: (1) Are these effects evident in children who are more representative of the general community? (2) To what extent do sleep problems associated with prenatal nicotine exposure persist into adolescence and adulthood?

The current paper examines the association between prenatal and postnatal maternal smoking, and offspring sleep problems in a large longitudinal community birth cohort study. We aimed to examine if exposure to prenatal maternal smoking increased the risk of sleep problems and snoring in offspring from 5 to 21 years, comparing this to the effect of postnatal maternal smoking on offspring sleep problems.

\section{Methods}

\section{Study design and population}

The Mater-University of Queensland Study of Pregnancy (MUSP) comprises a birth cohort of 7223 singleton infants born during 1981-83, with mothers being enrolled at the first antenatal visit (average 18 weeks gestation) [28]. Questionnaires were completed by mothers at enrolment, delivery, 6 months, and 5 years and by both mothers and offspring at 14 and 21 years (Additional files $1,2,3,4,5,6$, and 7). Numbers vary depending on the follow-up stage and sleep items.

\section{Standard protocol approvals, registrations, and patient consent}

The study was approved by the Human Research Ethics Committees of the Mater Hospital and The University of Queensland, with written informed consent being obtained from the mother at each stage of follow-up and from the youth at 21 years.

\section{Maternal smoking status}

Maternal smoking pattern over the previous week was examined in maternal questionnaires at the first clinic visit (FCV) (average 18 weeks gestation), 3-5 days after delivery, 6 months, 5 years and 14 years. Mothers were asked to record whether they smoked (yes or no) and if yes, their frequency and quantity of smoking in the previous week. Mothers were also asked at the FCV about whether and how much they smoked before they became pregnant. At 3-5 days after delivery, mothers were asked to recall their smoking level during the last trimester.

Information on maternal smoking was gathered in circumstances designed to maximize the accuracy of the data. This involved interviews conducted within a clinical setting, assurances of confidentiality, detailed questions, and trained interviewers. Reports do vary as to the accuracy of self-reported smoking among pregnant women. Significant agreement between self-reported smoking and serum cotinine levels (the major metabolite of nicotine) has been found [29, 30]. However, varying levels of under-reporting of smoking by pregnant women have been noted [31,32] and it is important to acknowledge the importance of the setting in which information is collected. This is highlighted by Carabello and colleagues [33] whose findings from a population-based survey of adults regarding their smoking status attest to the accuracy of self-reported smoking status if collected in a private medial setting. Pickett and colleagues [34] illustrate the complex nature of this issue, as their prospective research of pregnant women involved repeated measures of both self-reported smoking status and that based on cotinine levels. They concluded that in epidemiological studies where the intensity and timing of exposure is of particular interest, self-reported smoking status provides a valid measure of fetal exposure. The information was collected in the early 1980's when the prevalence and extent of smoking were higher and the issue was less prominent as a public health concern. Any potential bias is likely to lead to underreporting of cigarette use, with reduction of effect size.

\section{Prenatal smoking}

The category of prenatal smoking included mothers who reported smoking in early or late pregnancy and other 
times. Maternal smoking status was categorised as 'never smoked at any stage of the study' and 'smoked during pregnancy' (i.e. smoked in either early or late pregnancy and other times).

\section{Postnatal smoking}

The final category consisted of women who smoked postnatally but not during or before pregnancy (women who responded "no" to smoking before pregnancy, at FCV and third trimester but "yes" at 6 -months, 5 years or 14 years). The offspring whose mothers smoked during pregnancy and other times were exposed to the effects of maternal smoking whilst in utero as well as the effects of maternal smoking during childhood whereas the offspring of mothers who smoked postnatally but not during or before pregnancy were exposed to passive maternal smoking in infancy/childhood only. This enabled examination of the effects of in utero exposure to smoking over and above the effects of exposure to maternal smoking during early post-natal and childhood development. These categories are mutually exclusive. Women who smoked only before pregnancy were excluded.

\section{Offspring sleep problems}

At 5 years, mothers were asked how often their child had experienced trouble sleeping over the previous year, rated as often, sometimes, and never/rarely. At 14 years, mothers completed the Child Behaviour Checklist and the youth completed the Youth Self Report [35]. These assessments were chosen because they cover broad domains of mental health and child behavioural issues, they have established reliability and validity [35-37] and they have been widely used across many countries. The YSR is a standardized self-report questionnaire for adolescents aged from 11 to 18 years. The CBCL is a maternal report questionnaire that assesses the same behavioural subscales as the YSR [38]. Both scales contain the same five common items examining different aspects of sleep initiation and maintenance, parasomnias, and daytime tiredness over the previous 6 months. These five items were "trouble sleeping", "sleeps less than most kids", "nightmares", "sleeps more than most kids", and "overtired", with each item rated as often, sometimes, and rarely/never. "Talks or walks in sleep" was an additional question in the maternal CBCL. Mothers were also asked if their child had snored over the previous year. At 21 years many, though not all, of the items of the Pittsburgh sleep inventory [39] were administered to the young adult, as well as additional sleep questionnaire items. Four questions examined difficulties in initiating or maintaining sleep (trouble sleeping, sleep quality, restless sleep and night waking) and three questions examined daytime somnolence (trouble staying awake, day time drowsiness and overtired). Young adults also reported nightmares and snoring. Presence of problems was rated over the previous month.

We created composite indicators of sleep problems at 14 and 21 years, separately for maternal reported sleep items, youth reported sleep items and young adult reported sleep items. For sleep items (e.g. snoring) with a response option of 'yes', a score of ' 1 ' was assigned, and ' 0 ' for a response of 'no'. Other items, with response options in three categories, were assigned ' 0 ' for 'rarely/ never' or equivalent response, ' 1 ' for 'sometimes' or equivalent response, and ' 2 ' otherwise. All the items were summed after this scoring. The overall score was grouped into three categories as follows: 'lower 20\%, 'middle 20-80\%, and upper 20\%, with upper $20 \%$ having the highest number of sleep symptoms.

\section{Confounders and mediators}

Two groups of factors were examined: These were (i) other pregnancy lifestyle exposures and (ii) social and maternal factors. (i) Other pregnancy exposures examined were alcohol, tea and coffee. At the first pregnancy visit and within 1-3 days of birth, questionnaire items examined amount and frequency of alcohol intake (classified as nil, <one glass a day and $>$ one glass a day). Few mothers drank heavily. Coffee and tea each had four categories of none, 1, 2-3 or $\geq 4$ cups per day. Analyses were undertaken combining tea and coffee consumption and also examining their effect on offspring sleep separately. Only $2 \%$ of mothers reported using marijuana in pregnancy and analysing the data with and without this group produced no differences in the results. (ii) Social and demographic factors were maternal age and level of education, and family income at the FCV. The cut-off for low income levels was the lowest approximate third, depending upon the distribution. At the first antenatal visit mothers were asked four questions concerning whether the pregnancy was planned or wanted and classified as planned/wanted, unplanned/unwanted. Duration of breastfeeding was reported at the six-month follow-up and classified as nil, $<4$ months or $>4$ months.

\section{Statistical analyses}

The relationship between the maternal smoking variable ( 3 categories) and the 22 sleep measures at different follow-up phases (refer Table 2) was initially examined, with the chi squared test being administered for statistical significance. As each test reflected the initial study hypothesis, a two tailed $P$-value of $<0.05$ was taken to indicate initial statistical significance. However, due to multiple statistical comparisons, the effect of applying the Bonferroni correction was also examined. The relationship between maternal smoking and the eight sleep questions significant in this initial analysis is 
described in Table 2. To increase the statistical precision, for some outcomes we combined 'sometimes' and 'often' responses as one category (see Table 3) for the multivariable analyses. A sensitivity analysis was conducted to examine these results further. Of women who smoked cigarettes in pregnancy, more than half of them reported smoking $\geq 10$ cigarettes daily. No dose-response relationship was found. Additionally, as some of the cell frequencies were small, especially for the postnatal only smoking group, in the adjusted analyses we considered coffee, tea, alcohol in pregnancy, maternal age and education. Combining tea and coffee or considering them separately did not have any impact on the results. In the sensitivity analysis, we added other confounding factors and found the effect size remained consistent. An adjusted analysis was performed using multinomial logistic regression examining sequentially the effects of other pregnancy lifestyle exposures, social factors and maternal factors, with all factors included in a final fully adjusted model. In these multinomial logistic models, the groups of prenatal exposure, and postnatal exposure, were contrasted to never smoking mothers as the reference category.

\section{Results}

\section{Descriptive analyses}

Table 1 describes the total birth cohort and the study group at each stage of follow-up. Mothers of children lost to follow-up were more likely to be younger, less well educated, more financially disadvantaged and the children more likely to be of birthweight $<2500 \mathrm{~g}$ or gestation < 37 weeks. Of 3954 women who prospectively reported their smoking status from pregnancy to 14 years follow-up, 55\% never smoked, $41 \%$ smoked at some stage of pregnancy and other time and $4 \%$ smoked after pregnancy but not during or before pregnancy.

\section{Bivariate association between maternal smoking status and offspring sleeping}

Table 2 provides an overview of the 22 sleep questions ordered according to their follow-up phase, their distribution, and the level of statistical significance for their overall association with maternal smoking status during and after pregnancy. Eight of the sleep measures were initially significant at $P<0.05$, five of these at 14 years and three at 21 years. At 14 years the significant associations were: mother reports of talking or walking in sleep $(P<0.001)$, sleep more than other kids $(P=0.044)$ and snoring over the last year $(P=0.001)$. Youth-reported nightmares at 14 years was associated with maternal smoking in utero $(P=0.01)$. At 21 years, young adult-reported nightmares $(P=0.01)$ and being restless and trouble staying awake $\mathrm{p}(P=0.017)$ were significant.
There was no association between troubles sleeping at five years and maternal smoking. When the Bonferroni test was applied to the initial 24 comparisons, walking and talking in sleep retained significance. Each of the eight overall sleep measures was further examined for an interaction between smoking and gender and no interaction terms were significant.

\section{Multivariable analyses}

In Table 3, the strength of relationship between three mutually exclusive categories of maternal smoking status (no smoking as the reference category) and the eight sleeping outcomes are shown adjusted for other pregnancy exposures, and maternal and social factors. For maternal smoking during pregnancy and other times, mother-reported talks/walks in sleep and youth-reported nightmares were more likely (OR and 95\% CI: $1.23,1.04-1.46$ and $1.23,1.03-1.46$ respectively) whereas problems staying awake at 21 years was less likely (OR and 95\% CI: $0.80,0.65-0.98$ ). For mothers who smoked postnatally but not before or during pregnancy, maternal reported offspring snoring at 14 years was more likely (OR and 95\% CI: 1.53, 1.06-2.23). The composite sleep variables in Table 4 show that the top $20 \%$ and middle $20-80 \%$ of maternal reports of sleep problems at 14 years were more likely in the offspring of both maternal smoking groups in the adjusted analysis (OR and 95\% CI: 1.26, 1.05-1.50 and 1.36, 1.05, 1.76, respectively). For youth-reported composite sleep problems at 14 years, the only significant association in the adjusted analysis is with smoking in pregnancy and at other times (OR and 95\% CI: 1.29, 1.02-1.64). At 21 years, no associations are significant in the adjusted analysis.

\section{Discussion}

Compared to the offspring of mothers who were non-smokers on all occasions, those exposed to maternal smoking were more likely to have changes in 5 individual offspring sleep items after adjusting for confounders, 4 of these at 14 years and one item at 21 years. Offspring exposed to maternal smoking whilst in utero were more likely at 14 years to have parasomnias as evidenced by maternal-reported 'talks and walks in sleep' and youth-reported nightmares. Offspring snoring and sleeping less at 14 years were associated with mothers who did not smoke in pregnancy though smoked at other times. At 21 years, offspring of mothers who smoked in pregnancy and at other times were less likely to report difficulties staying awake. For the composite sleep measures at 14 years, offspring exposed to smoking in pregnancy and at other times were more likely to be in the highest quintile for sleep problems as reported by both youth and their mothers. According to maternal 
Table 1 Comparison of birth cohort and study group at each stage of follow-up

\begin{tabular}{|c|c|c|c|c|c|}
\hline \multirow{2}{*}{$\begin{array}{l}\text { Variable } \\
\text { Maternal age (yrs) }\end{array}$} & \multicolumn{2}{|c|}{$\begin{array}{l}\text { Birth cohort }^{\mathrm{a}} \\
(n=7223) n \%\end{array}$} & \multirow[t]{2}{*}{$\begin{array}{l}5 \text { years } \\
(n=4249) \% \\
\end{array}$} & \multirow[t]{2}{*}{$\begin{array}{l}14 \text { years } \\
(n=4155) \% \\
\end{array}$} & \multirow[t]{2}{*}{$\begin{array}{l}21 \text { years } \\
(n=2913) \% \\
\end{array}$} \\
\hline & & & & & \\
\hline $15-19$ & 1184 & 16.4 & 12.4 & 12.5 & 11.4 \\
\hline $20-35$ & 5726 & 79.3 & 83.2 & 83.2 & 83.8 \\
\hline$>35$ & 313 & 4.3 & 4.4 & 4.3 & 4.7 \\
\hline \multicolumn{6}{|c|}{ Level maternal education } \\
\hline Incomplete high & 1305 & 18.2 & 16.3 & 16.0 & 15.2 \\
\hline Complete high & 4609 & 64.3 & 64.4 & 64.6 & 64.3 \\
\hline Post high & 1256 & 17.5 & 19.4 & 19.4 & 20.5 \\
\hline \multicolumn{6}{|c|}{ Family income (antenatal) } \\
\hline$>\$ 10,400$ & 4441 & 65.8 & 71.3 & 71.6 & 72.3 \\
\hline$<\$ 10,400$ & 2308 & 34.2 & 28.7 & 28.4 & 27.7 \\
\hline \multicolumn{6}{|l|}{ Maternal depression } \\
\hline No & 6262 & 88.4 & 90.7 & 90.8 & 91.7 \\
\hline Yes & 823 & 11.6 & 9.3 & 9.2 & 8.3 \\
\hline \multicolumn{6}{|l|}{ Gender } \\
\hline Male & 3758 & 52.0 & 52.1 & 52.1 & 47.5 \\
\hline Female & 3465 & 48.0 & 47.9 & 47.9 & 52.5 \\
\hline \multicolumn{6}{|l|}{ Birth weight } \\
\hline$>2500 \mathrm{~g}$ & 6911 & 95.7 & 96.2 & 96.2 & 96.5 \\
\hline$<2500 \mathrm{~g}$ & 311 & 4.3 & 3.8 & 3.8 & 3.5 \\
\hline \multicolumn{6}{|l|}{ Gestation } \\
\hline$>37$ wks & 6927 & 95.9 & 96.1 & 96.1 & 96.1 \\
\hline$<37$ wks & 296 & 4.1 & 3.9 & 3.9 & 3.9 \\
\hline
\end{tabular}

${ }^{a}$ Numbers vary slightly due to missing data

report, offspring exposed to smoking in the postnatal period only and not during pregnancy were also more likely to be in the highest quintile for sleep problems.

It is noteworthy that the parasomnias (walking and talking in sleep and nightmares) occurred in offspring whose mothers smoked during pregnancy and at other times but were not evident in the offspring who were not exposed to smoking during pregnancy. Stone et al's [27] prospective longitudinal study of children from a high risk sample with multiple exposures found that postnatal smoking did not contribute significantly to the explanation of a composite measure of sleep problems across the first 12 years. Similarly, in our study, the composite sleep measure showed that offspring exposed to maternal smoking in utero were more likely to have sleep problems at 14 years as reported by both the youth and their mothers.

Prenatal smoking is known to be associated with later behaviour problems in children $[9,40]$ that may potentially influence parasomnias. The findings for walks/talks in sleep, though not nightmares, were independent of mental health at 14 years measured by the YSR. Walking and talking in sleep are parasomnias that occur in non-REM sleep and reflect transitions from deep to light sleep. The literature suggests that walking in sleep decreases after adolescence to adult levels of up to $4 \%$ $[41,42]$. Although prevalence decreases with age, the potential for serious injury and aggression involving the individual and others [43], as well as the implications for daytime functioning deficits due to poorer sleep quality suggests that this warrants further investigation. This association may be casual and reflect mechanisms discussed earlier including epigenetic effects of nicotine on the developing neurotransmitter systems. Sleepwalking is increased in Parkinson's disease where an imbalance of neurotransmitters exists due to loss of dopamine producing neurons [1]. A genetic predisposition [2] is also possible. Our study supports that exposure to maternal smoking in utero but not postnatally may result in neurodevelopmental changes, of which one manifestation is an increased risk of parasomnias.

The lack of significant findings for trouble sleeping at 5 years may reflect the limitation and imprecision of using a one-item measure given their inconsistency with 
Table 2 Distribution of sleep measures at 6-months, 5, 14 and 21 years and overall significance of relationship to smoking (never, smoked postnatally but not in pregnancy and pre-pregnancy, pregnancy+other times)

\begin{tabular}{|c|c|c|c|c|c|}
\hline & & Maternal Smoking & & & \\
\hline & $n(\%)$ & Never $(n=2174) \%$ & $\begin{array}{l}\text { Smoked postnatally but not in pregnancy } \\
\text { and pre-pregnancy }(n=170) \%\end{array}$ & $\begin{array}{l}\text { Smoked in pregnancy + other } \\
\text { times }(n=1610) \%\end{array}$ & $P$ \\
\hline 6-months & & & & & \\
\hline Sleeplessness & & & & & \\
\hline Almost everyday & $282(7.2)$ & $145(6.8)$ & $6(3.6)$ & $131(8.3)$ & \\
\hline Few times a week & $419(10.7)$ & $213(9.9)$ & $20(11.9)$ & $186(11.7)$ & \\
\hline Few times a month & $458(11.7)$ & $264(12.3)$ & $19(11.3)$ & $175(11.0)$ & \\
\hline Few times Rarely/never & $2744(70.3)$ & $1527(71.1)$ & $113(73.2)$ & $1094(68.9)$ & 0.083 \\
\hline 5-years (past year) & & & & & \\
\hline Trouble sleeping & & & & & \\
\hline often & $108(2.7)$ & $52(2.4)$ & $4(2.4)$ & $52(3.3)$ & \\
\hline sometimes & $839(21.3)$ & $453(20.9)$ & $31(18.2)$ & $355(22.2)$ & \\
\hline rarely/never & $2996(76.0)$ & $1666(76.7)$ & $135(79.4)$ & 1195 (74.6) & 0.302 \\
\hline 14 years (mother) & & & & & \\
\hline Trouble sleeping & & & & & \\
\hline often & $69(1.7)$ & $40(1.8)$ & $4(2.3)$ & $25(1.6)$ & \\
\hline sometimes & $513(12.9)$ & $272(12.5)$ & $29(17.0)$ & $212(13.1)$ & \\
\hline rarely/never & $387(85.3)$ & $1873(85.7)$ & $138(80.7)$ & $1376(85.30)$ & 0.426 \\
\hline Sleeps less & & & & & \\
\hline often & $92(2.3)$ & $48(2.2)$ & $6(3.5)$ & $38(2.4)$ & \\
\hline sometimes & $379(9.5)$ & $183(8.4)$ & $23(13.5)$ & $173(10.7)$ & \\
\hline rarely/never & $3503(88.2)$ & 1956 (89.4) & $142(83.0)$ & 1405 (86.9) & 0.032 \\
\hline Nightmares & & & & & \\
\hline often & $35(0.9)$ & $15(0.7)$ & $4(2.4)$ & $16(1.0)$ & \\
\hline sometimes & $592(14.9)$ & $306(14.0)$ & $26(15.3)$ & $260(16.1)$ & \\
\hline rarely/never & 3341 (84.2) & 1865 (85.3) & $140(82.3)$ & $1336(82.9)$ & 0.063 \\
\hline Talks/walks & & & & & \\
\hline often & $133(3.4)$ & $49(2.2)$ & $8(4.7)$ & $76(4.7)$ & \\
\hline sometimes & $952(24.0)$ & $498(22.8)$ & 37 (21.6) & $417(25.9)$ & \\
\hline rarely/never & 2881 (72.6) & $1636(74.9)$ & $126(73.7)$ & 1119 (69.4) & $<0.001$ \\
\hline Sleeps more & & & & & \\
\hline often & $96(2.4)$ & $54(2.5)$ & $2(1.2)$ & $40(2.5)$ & \\
\hline sometimes & $572(14.4)$ & $282(12.9)$ & $28(16.4)$ & $262(16.2)$ & 0.044 \\
\hline rarely/never & $3300(83.2)$ & $1845(84.6)$ & $141(82.5)$ & 1314 (81.3) & \\
\hline Overtired & & & & & \\
\hline often & $134(3.4)$ & $76(3.5)$ & $5(3.0)$ & $53(3.3)$ & \\
\hline sometimes & $1630(41.2)$ & $897(41.1)$ & $80(47.1)$ & $653(40.6)$ & \\
\hline rarely/never & $2197(55.5)$ & $1210(55.4)$ & $85(50.0)$ & $902(56.1)$ & 0.594 \\
\hline Snoring & & & & & \\
\hline Yes & $932(23.5)$ & $463(21.3)$ & $53(30.8)$ & $416(25.8)$ & \\
\hline No & $3032(76.5)$ & 1715 (78.7) & $119(69.2)$ & 1198 (74.2) & $<0.001$ \\
\hline
\end{tabular}


Table 2 Distribution of sleep measures at 6-months, 5, 14 and 21 years and overall significance of relationship to smoking (never, smoked postnatally but not in pregnancy and pre-pregnancy, pregnancy+other times) (Continued)

\begin{tabular}{|c|c|c|c|c|c|}
\hline & & Maternal Smoking & & & \\
\hline & $n(\%)$ & Never $(n=2174) \%$ & $\begin{array}{l}\text { Smoked postnatally but not in pregnancy } \\
\text { and pre-pregnancy }(n=170) \%\end{array}$ & $\begin{array}{l}\text { Smoked in pregnancy + other } \\
\text { times }(n=1610) \%\end{array}$ & P \\
\hline 14 years (youth) & & & & & \\
\hline Trouble sleeping & & & & & \\
\hline often & $216(5.8)$ & $127(6.1)$ & $7(4.2)$ & $82(5.5)$ & \\
\hline sometimes & $1276(34.1)$ & $681(32.6)$ & $61(36.8)$ & $534(36.1)$ & \\
\hline rarely/never & $2246(60.1)$ & $1284(61.4)$ & $98(59.0)$ & $864(58.4)$ & 0.200 \\
\hline Sleep less & & & & & \\
\hline often & $304(7.7)$ & $152(7.0)$ & $13(7.6)$ & $139(8.6)$ & \\
\hline sometimes & 1199 (30.3) & $662(30.5)$ & $51(30.2)$ & $486(30.2)$ & \\
\hline rarely/never & $2450(62.0)$ & $1356(62.5)$ & $107(62.6)$ & $987(61.2)$ & 0.485 \\
\hline Nightmares & & & & & \\
\hline often & $107(2.7)$ & $46(2.1)$ & $6(3.5)$ & $55(3.4)$ & \\
\hline sometimes & $971(24.6)$ & $502(23.1)$ & $43(25.3)$ & $426(26.5)$ & \\
\hline never & $2876(72.7)$ & $1626(74.8)$ & $121(71.2)$ & $1129(70.1)$ & 0.010 \\
\hline Sleeps more & & & & & \\
\hline often & $282(7.1)$ & $144(6.7)$ & $8(4.7)$ & $130(8.1)$ & \\
\hline sometimes & $1183(30.0)$ & $664(30.7)$ & $50(29.2)$ & $469(29.1)$ & \\
\hline rarely/never & $2484(62.9)$ & $1358(62.7)$ & $113(66.1)$ & $1013(62.8)$ & 0.269 \\
\hline Overtired & & & & & \\
\hline often & $380(9.6)$ & $20(9.5)$ & $11(6.5)$ & $164(10.2)$ & \\
\hline sometimes & $1983(50.3)$ & $1089(50.3)$ & $94(55.3)$ & $800(49.8)$ & \\
\hline rarely/never & $1578(40.0)$ & $872(40.3)$ & 65 (38.2) & $641(39.9)$ & 0.482 \\
\hline 21 years & & $(n=1611)$ & $(n=100)$ & $(n=1081)$ & \\
\hline Trouble sleeping & & & & & \\
\hline often & $366(13.1)$ & $192(11.9)$ & $13(13.0)$ & $161(14.9)$ & \\
\hline somewhat & $1090(38.0)$ & $635(39.4)$ & $39(39.0)$ & $416(38.5)$ & \\
\hline not true & $1336(47.9)$ & $784(48.7)$ & $48(48.0)$ & $504(46.6)$ & 0.279 \\
\hline Nightmares & & & & & \\
\hline often & $110(3.9)$ & $56(3.5)$ & $3(3.0)$ & $51(4.7)$ & \\
\hline somewhat & $592(21.2)$ & $320(19.9)$ & $11(11.0)$ & $261(24.1)$ & \\
\hline not true & $2089(74.9)$ & $1234(6.7)$ & $86(86.0)$ & $769(71.1)$ & 0.001 \\
\hline Overtired & & & & & \\
\hline often & 387 (13.9) & $220(13.7)$ & $15(15.3)$ & $152(14.0)$ & \\
\hline somewhat & $1310(47.0)$ & $761(47.5)$ & $43(43.9)$ & $506(46.5)$ & \\
\hline not true & $1093(39.2)$ & $622(38.8)$ & $40(40.8)$ & 431 (39.6) & 0.952 \\
\hline Restless sleep & & & & & \\
\hline Three+ per week & $444(16.0)$ & $238(15.0)$ & $15(15.0)$ & $191(17.7)$ & \\
\hline Once or twice/week & $940(34.0)$ & $534(33.6)$ & $24(24.0)$ & $382(35.4)$ & \\
\hline < once/week & $1385(50.0)$ & $819(51.5)$ & $61(61.0)$ & $505(46.9)$ & 0.017 \\
\hline Night walking & & & & & \\
\hline Three+ per week & $541(19.6)$ & $303(19.0)$ & $13(13.4)$ & $225(20.9)$ & \\
\hline Once or twice/week & $612(22.1)$ & $343(21.6)$ & $22(23.7)$ & $247(22.9)$ & \\
\hline < once/week & $1613(58.3)$ & $946(59.4)$ & $62(63.9)$ & $605(56.2)$ & 0.252 \\
\hline
\end{tabular}


Table 2 Distribution of sleep measures at 6-months, 5, 14 and 21 years and overall significance of relationship to smoking (never, smoked postnatally but not in pregnancy and pre-pregnancy, pregnancy+other times) (Continued)

\begin{tabular}{|c|c|c|c|c|c|}
\hline & \multirow[b]{2}{*}{$n(\%)$} & \multicolumn{3}{|l|}{ Maternal Smoking } & \multirow[b]{2}{*}{$P$} \\
\hline & & Never $(n=2174) \%$ & $\begin{array}{l}\text { Smoked postnatally but not in pregnancy } \\
\text { and pre-pregnancy }(n=170) \%\end{array}$ & $\begin{array}{l}\text { Smoked in pregnancy + other } \\
\text { times }(n=1610) \%\end{array}$ & \\
\hline \multicolumn{6}{|l|}{ Drowsy at daytime } \\
\hline Three+ per week & $636(22.9)$ & $363(22.8)$ & $16(16.2)$ & $257(23.8)$ & \\
\hline Once or twice/week & $1136(40.9)$ & $642(40.3)$ & $42(42.4)$ & $452(41.8)$ & \\
\hline < once/week & $1003(36.1)$ & $590(37.0)$ & $41(41.4)$ & $372(34.4)$ & 0.314 \\
\hline \multicolumn{6}{|l|}{ Trouble staying awake } \\
\hline At least once/week & $229(8.6)$ & $140(8.7)$ & $4(4.0)$ & $85(7.8)$ & \\
\hline < once/week & $621(22.2)$ & $386(23.9)$ & $21(20.8)$ & $214(19.6)$ & \\
\hline No & $1954(69.7)$ & $1087(69.4)$ & $76(75.3)$ & 791 (72.6) & 0.044 \\
\hline \multicolumn{6}{|l|}{ Sleep quality } \\
\hline Largely bad & $82(2.9)$ & $38(2.4)$ & $3(3.2)$ & $41(3.8)$ & \\
\hline Fairly bad & $452(16.1)$ & $257(16.0)$ & $11(10.9)$ & $184(16.9)$ & \\
\hline Fairly/very good & $2268(81.0)$ & 1315 (81.7) & $87(86.1)$ & $866(79.4)$ & 0.226 \\
\hline \multicolumn{6}{|l|}{ Snoring } \\
\hline Three+/week & $183(6.7)$ & $100(6.4)$ & $3(3.1)$ & $80(7.5)$ & \\
\hline Once to twice/week & $232(8.5)$ & $126(8.0)$ & $8(8.3$ & $98(9.2)$ & \\
\hline$<$ Once/week & $2319(84.8)$ & $1344(85.6)$ & $86(88.7$ & $889(83.3)$ & 0.316 \\
\hline
\end{tabular}

previous research [26, 27]. However, this study cohort differs in not being high risk. At 14 and 21 years, several sleep measures were evaluated. Although these were self or maternal report single-item measures, they included a question on trouble sleeping that Gregory et al. [44] reported to be associated with results from more formal sleep studies. Within this cohort, trouble sleeping behaviours have previously been found to be associated with sleep problems persisting from a young age to adulthood [45].

\section{Strengths and limitations}

Several features of the current study make the results noteworthy. This is the first longitudinal study to examine sleep problems associated with prenatal maternal smoking and postnatal smoking across several developmental periods in a large community sample. This study is best able to examine consequences of prenatal smoking on sleep in adolescence and young adulthood and control for exposure to parental smoking during childhood. The only previous longitudinal research examined outcomes up to 12 years in a very different group - a high risk cohort with pregnancy exposures [27]. The analyses adjusted for a number of psychosocial characteristics that could potentially confound any relationship between maternal smoking and offspring sleep. The strategy for data analysis used in our study also has advantages for exposures such as cigarette use that are strongly correlated over time. Although we could examine the effect of maternal smoking during pregnancy on offspring sleep separately from smoking at other times, a limitation of this study is that level of smoking could not be evaluated using this methodology so a threshold effect with heavy prenatal smoking cannot be excluded. A further limitation is the lack of information on exposure to other sources of passive smoking including smoking by fathers. The exposure to second hand smoking by other people in the household may impact on the respiratory systems of the offspring resulting in increased risk of parasomnias and snoring. Smoking by others in the home, however, is likely to be correlated with maternal smoking and disentangling what is a direct effect of maternal smoking and a result of passive smoking was not possible in this study. While maternal smoking was measured only with self-reports, these involved detailed questions asked by trained interviewers in a confidential, clinical setting. There is therefore a possibility of a social desirability bias leading to under-reporting of smoking status.

Other limitations include the use of questionnaire measures to assess sleep and the level of attrition. We have previously assessed the impact of attrition using multiple imputation and sensitivity analyses, with little impact on the findings [28]. Comparisons to other cohort studies have also yielded similar results [46]. Attrition was more likely in those offspring whose mothers had adverse social circumstances and adjustment for these in our analysis made little difference to the findings. Moreover, the present results would only 


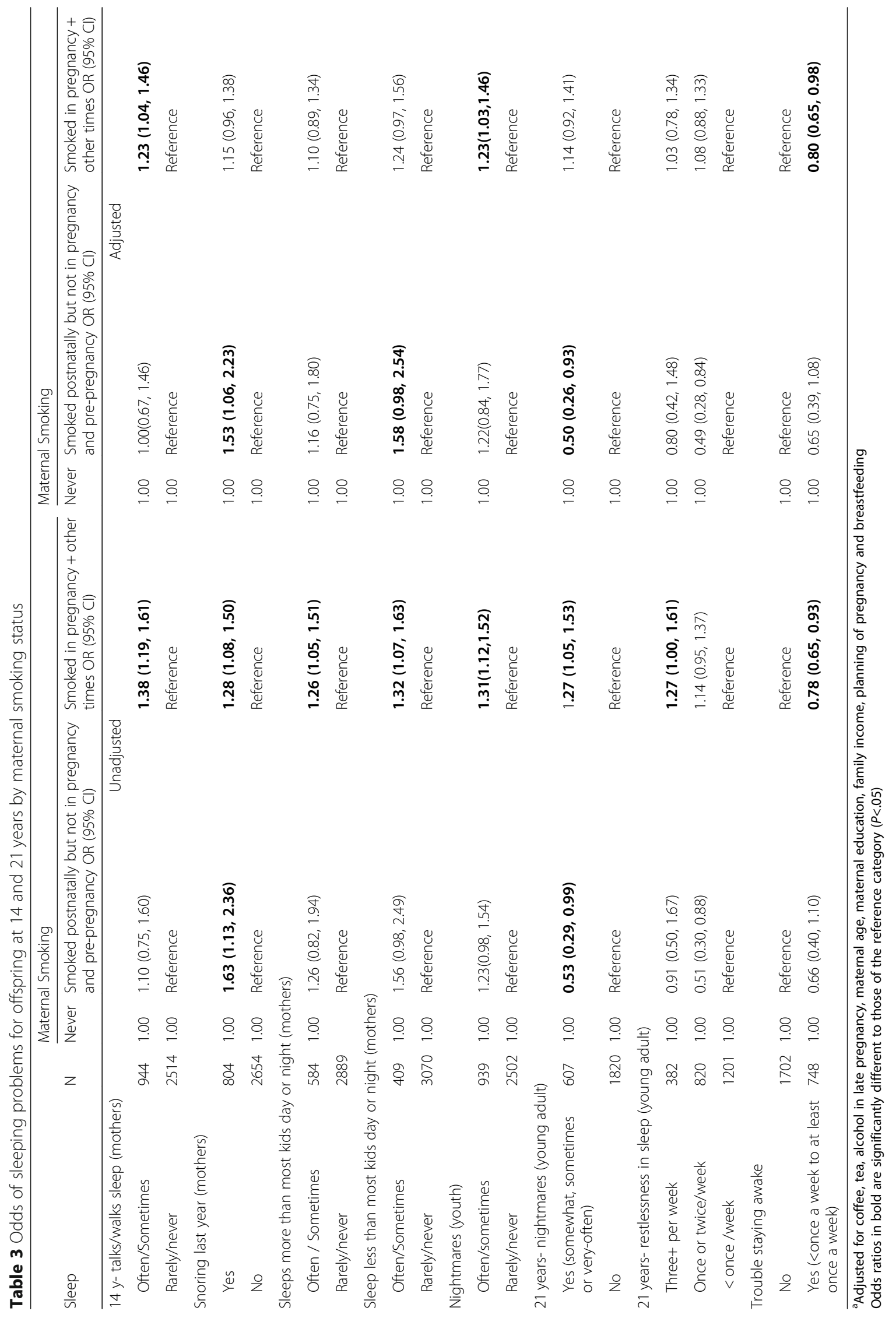




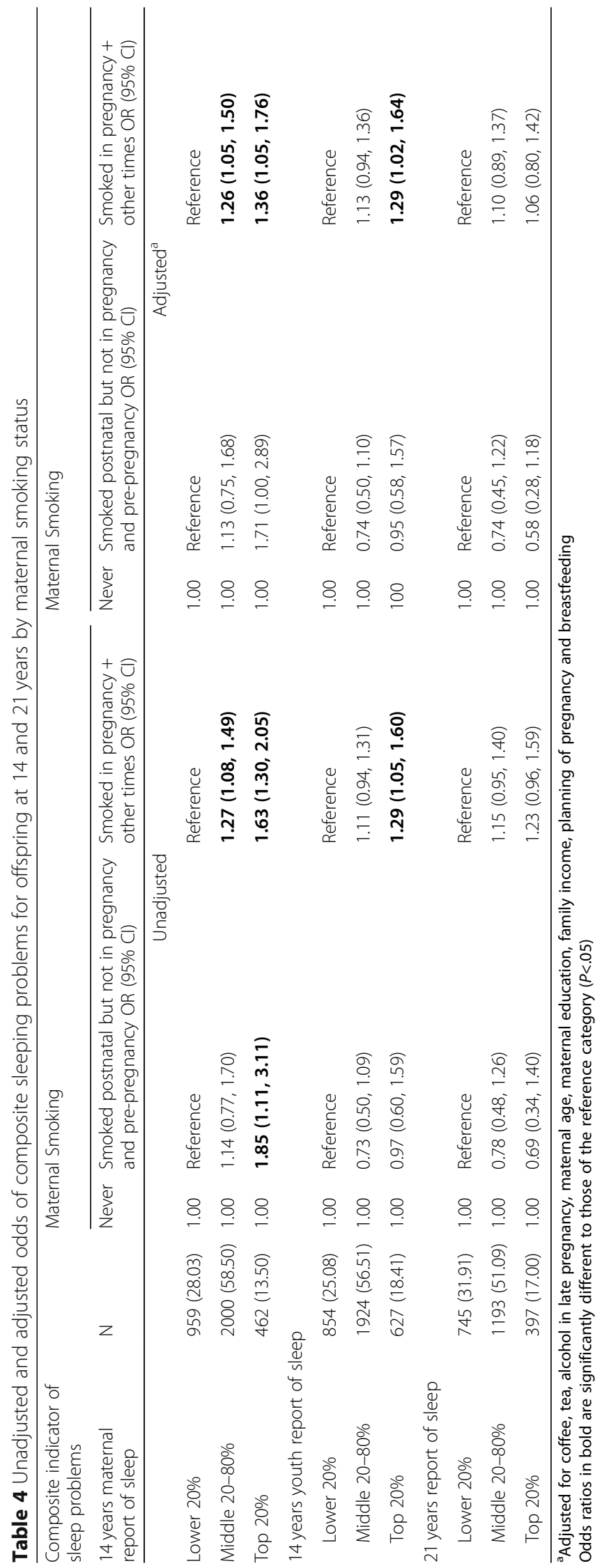


be biased if the associations were in the opposite direction in participants not assessed at each phase of the research which would be unlikely.

\section{Conclusions}

The association between prenatal maternal smoking and adolescent offspring parasomnias of walking in sleep and talking in sleep at 14 years have important clinical implications due to the potential for serious injury and aggression, as well as consequences for sleep quality and daytime functioning, as noted previously. This study supports the research of others that exposure to maternal smoking in utero may affect neurodevelopment which has an impact on offspring even in the adolescent years. This is more evidence of the serious adverse effects of smoking which persist well beyond those direct effects on the individual and are associated with changes in other family members in systems of the body, the mechanisms by which warrant further investigation.

\section{Additional files}

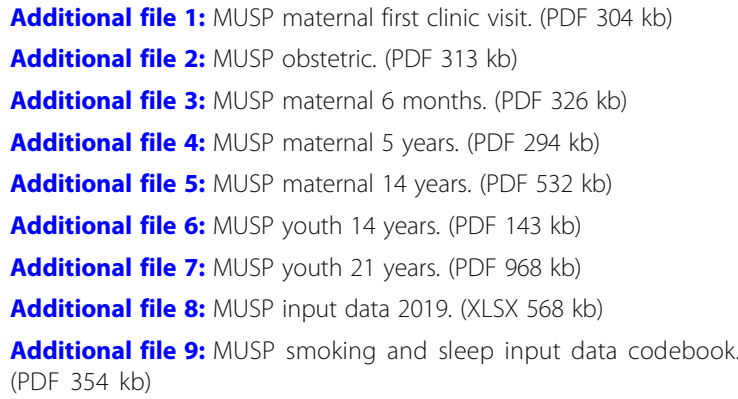

\section{Abbreviations}

CBCL: Child behaviour checklist; Cl: Confidence interval; MUSP: Mater University of Queensland Study of Pregnancy; OR: Odds ratio; YSR: Youth self report

\section{Acknowledgements}

We thank all participants in the study, the MUSP data collection team, and data manager, and The University of Queensland for helping to manage the data for the MUSP.

\section{Funding}

Financial support for the research was provided by the National Health and Medical Research Council (NHMRC), Australia. JGS is supported by a National Health and Medical Research Council Practitioner Fellowship Grant APP1105807.

\section{Availability of data and materials}

Data are available from the Mater-University of Queensland Study (URL: https:// social-science.uq.edu.au/mater-university-queensland-study-pregnancy) of Pregnancy. Questionnaires developed specifically for use in this study are provided as supplementary files (Additional files 8 and 9).

\section{Authors' contributions}

FOC participated in conceptualization of the study and drafted and critically revised the manuscript for important intellectual content; MOC participated in conceptualization of the study, data preparation, analysis and interpretation, and critically reviewed the manuscript; JGS participated in conceptualization of the study, interpretation of data and reviewed the manuscript; JN participated in the conceptualization of the study and critically reviewed the manuscript; AM participated in conceptualization of the study, data preparation, analysis and interpretation, and critically revised the manuscript. All authors read and approved the final manuscript.

\section{Authors' information}

FOC is an Associate Professor and health psychologist in the School of Applied Psychology, Griffith University; MOC is a paediatrician and is a Chief Investigator on the Mater University of Queensland Study of Pregnancy (MUSP); JGS is a Chief Investigator on the MUSP and a child and adolescent psychiatrist at the UQ Centre for Clinical Research; JN is a Chief Investigator on the MUSP, Director of the Queensland Alcohol and Drug Research and Education Centre (QADREC) and Professor of Sociology at The University of Queensland; AM is a Professor of Biostatistics in the School of Public Health, Faculty of Medicine and Biomedical Sciences, The University of Queensland.

\section{Ethics approval and consent to participate}

The study was approved by the Human Research Ethics Committees of the Mater Hospital and The University of Queensland, with written informed consent being obtained from the mother at each stage of follow-up and from the youth at 21 years.

\section{Consent for publication}

Not applicable.

\section{Competing interests}

The authors declare that they have no competing interests.

\section{Publisher's Note}

Springer Nature remains neutral with regard to jurisdictional claims in published maps and institutional affiliations.

\section{Author details}

${ }^{1}$ School of Applied Psychology and Menzies Health Institute, Griffith University, Gold Coast 4222, Australia. ${ }^{2}$ School of Medicine, The University of Queensland, Brisbane 4101, Australia. ${ }^{3}$ Faculty of Medicine, The University of Queensland Centre for Clinical Research and Metro North Mental Health,

Royal Brisbane and Women's Hospital, QLD, Brisbane 4029, Australia. ${ }^{4}$ School of Public Health, The University of Queensland, QLD, Brisbane 4006, Australia. ${ }^{5}$ School of Social Science, The University of Queensland, Brisbane 4072, Australia.

Received: 13 December 2018 Accepted: 20 February 2019

Published online: 06 March 2019

\section{References}

1. World Health Organization. WHO technical meeting on sleep and health. In: Bonn: European Centre for environment and health; 2004.

2. O'Callaghan FV, Mamun AA, O'Callaghan M, Clavarino A, Williams GM, Bor W, Heussler H, Najman JM. The link between sleep problems in early childhood and attention problems at 5 and 14 years: evidence from a birth cohort study. Early Hum Dev. 2010;86:419-24.

3. Gregory AM. Sleep problems in childhood predict neuropsychological functioning in adolescence. Pediatrics. 2009;123:1171-6.

4. Randazzo AC, Muehlbach MJ, Schweitzer PK, Walsh JK. Cognitive function following acute sleep restriction in children ages 10-14. Sleep. 1998;21:861-8.

5. Fallone G, Seifer R, Acebo C, Carskadon MA. Prolonged sleep restriction in 11 - and 12 -year old children: effects on behaviour, sleepiness, and mood. Sleep. 2000;23(Suppl 2):S28.

6. Wong MM, Brower KJ, Zucker RA. Childhood sleep problems, early onset of substance use and behavioural problems in adolescence. Sleep Med. 2009;10:787-96.

7. Szentkiralyi A, Madarasz CZ, Novak M. Sleep disorders: impact on daytime functioning and quality of life. Expert Rev Pharmacoecon Outcome Res. 2009;9:49-64

8. Stepanski EJ. The effect of sleep fragmentation on daytime function. Sleep. 2002;25:268-76.

9. Ernst M, Moolchan ET, Robinson ML. Behavioural and neural consequences of prenatal exposure to nicotine. J Am Acad Child Adolesc Psychiatry. 2007:40:630-41. 
10. Gilman SE, Gardener H, Buka SL. Maternal smoking during pregnancy and children's cognitive and physical development: a causal risk factor? Am J Epidemiol. 2008;168:522-31.

11. Maughan B, Taylor C, Taylor A. Pregnancy smoking and childhood conduct problems: a causal association? J Child Psychol Psychiatry. 2001;42:1021-8.

12. Oken E, Levitan EB, Gillman MW. Maternal smoking during pregnancy and child overweight. Int J Obes. 2008;32(2):201-10.

13. Wakschlag LS, Pickett KE, Cooke E Jr, Benowitz NL, Leventhal BL. Maternal smoking during pregnancy and severe antisocial behaviour in offspring: a review. Am J Public Health. 2002;92:966-74.

14. O'Callaghan FV, Mamun AA, O'Callaghan M, Alati R, Najman JM, Williams GM, Bor W. Maternal smoking during pregnancy predicts nicotine disorder (dependence or withdrawal) in young adults - a birth cohort study. Aust NZ Public Health. 2009;33:371-7.

15. Mortensen EL, Michaelsen KF, Sanders SA. Reinisch JM. A dose-response relationship between maternal smoking during late pregnancy and adult intelligence in male offspring. Paediatr Perinat Epidemiol. 2005;19:4-11.

16. Beebe DW, Rausch J, Byars KC, Lanphear B, Yolton K. Persistent snoring in preschool children: predictors and behavioral and developmental correlates. Pediatrics. 2012;130:382-9.

17. O'Brien LM, Holbrook CR, Mervis CB, Klaus CJ, Bruner JL, Raffield TJ, Rutherford J, Mehl RC, Wang M, Tuell A, Hume BC, Gozal D. Sleep and neurobehavioral characteristics of 5- to 7-year-old children with parentally reported symptoms of attention-deficit/hyperactivity disorder. Pediatrics. 2003:111:554-63.

18. Sawnani H, Jackson T, Murphy T, Beckerman R, Simakajornboon N. The effect of maternal smoking on respiratory and arousal patterns in preterm infants during sleep. Am J Respir Crit Care Med. 2004;169:733-8.

19. Yolton $K, X u$ Y, Khoury J, Succop P, Lanphear B, Beebe DW, Owens J. Associations between secondhand smoke exposure and sleep patterns in children. Pediatrics. 2010;125:e261-8.

20. Garcia-Rill E, Buchanan R, McKeon K, Skinner RD, Wallace T. Smoking during pregnancy: postnatal effects on arousal and attentional brain systems. Neurotoxicology. 2007;28:915-23.

21. Mennella JA, Yourshaw LM, Morgan LK. Breast feeding and smoking: shortterm. effects on infant feeding and sleep. Pediatrics. 2007:120:497-502.

22. Saint-Mleux B, Eggermann E, Bisetti A, Bayer L, Machard D, Jones BE, Mühlethaler M, Serafin M. Nicotinic enhancement of the noradrenergic inhibition of sleep-promoting neurons in the ventrolateral preopticarea. J Neurosci. 2004;24:63-7.

23. Abbott LC, Winzer-Serhan U. Smoking during pregnancy: lessons learned from epidemiological studies and experimental studies using animal models. Crit Rev Toxicol. 2012:42:279-303.

24. Knopik VS, Maccani MA, Francazio S, McGeary JE. The epigenetics of maternal cigarette smoking during pregnancy and effects on child development. Dev Psychopathol. 2012;24:1377-90.

25. Stephan-Blanchard E, Telliez F, Leke A, Djeddi D, Bach V, Libert J, Chardon K The influence of in utero exposure to smoking on sleep patterns in preterm neonates. Sleep. 2008:31:1683-9.

26. Stone KC, High PC, Miler-Lonca CL, LaGasse LL, Lester BM. Longitudinal study of maternal report of sleep problems in children with prenatal exposure to cocaine and other drugs. Behav Sleep Med. 2009;7:196-207.

27. Stone KC, LaGasse LL, Lester BM, Shankaran S, Bada HS, Bauer CR, Hammond JA. Sleep problems in children with prenatal substance exposure: the maternal lifestyle study. Arch Paediatr Adolesc Med. 2010;164:452-6.

28. Najman JM, Bor W, O'Callaghan M, Aird R, Shuttlewood G. Cohort profile: the Mater-University of Queensland study of pregnancy (MUSP). Int J Epidemiol. 2005;34:992-7.

29. Buka SL, Shenassa E, Niaura R. Elevated risk of tobacco dependence among offspring of mothers who smoked during pregnancy: a 30-year prospective study. Am J Psychiatry. 2003;160:1978-84.

30. McDonald SD, Perkins SL, Walker MC. Correlation between self-reported smoking status and serum cotinine during pregnancy. Addict Behav. 2005:30:853-7.

31. Lawrence T, Aveyard P, Croghan E. What happens to women's self-reported cigarette consumption and urinary cotinine levels in pregnancy? Addiction. 2003;98:1315-20

32. Shipton D, Tappin DM, Vadiveloo T, Crossley JA, Aitken DA, Chalmers J. Reliability of self reported smoking status by pregnant women for estimating smoking prevalence: a retrospective, cross sectional study. BMJ. 2009;339:b4347.
33. Caraballo RS, Giovino GA, Pechacek TF, Mowery PD. Factors associated with discrepancies between self-reports on cigarette smoking and measured serum cotinine levels among persons aged 17 years or older: third National Health and nutrition examination survey, 1988-1994. Am J Epidemiol. 2001;153:807-14.

34. Pickett KE, Rathouz PJ, Kasza K, Wakschlag LS, Wright R. Self-reported smoking, cotinine levels, and patterns of smoking in pregnancy. Paediatr Perinat Epidemiol. 2005;19:368-76.

35. Achenbach TM. Manual for the child behaviour checklist. Burlington: University of Vermont Department of Psychiatry; 1991.

36. Lowe LA. Using the child behavior checklist in assessing conduct disorder: issues of reliability and validity. Res Soc Work Pract. 1998;8:286-301.

37. Nakamura BJ, Ebesutani C, Bernstein A, Chorpita BF. Psychometric analysis of the child behavior checklist DSM-oriented scales. J Psychopathol Behav Assess. 2009:31:178-89.

38. Achenbach TM. Integrative guide for the 1991 CBCL/4-18, YSR, and TRF profiles. Burlington, VT: University of Vermont Department of Psychiatry; 1991.

39. Buysse DJ, Reynolds CF, Monk TH, Berman SR, Kupfer DJ. The Pittsburgh Sleep quality index: a new instrument for psychiatric practice and research. Psychiatry Res. 1988;28:193-213.

40. O'Callaghan FV, O'Callaghan M, Najman J, Williams G, Bor W, Alati R. Prediction of adolescent smoking from family and social risk factors at 5 years, and maternal smoking in pregnancy and at 5 and 14 years. Addiction. 2006;101:282-90.

41. Guilleminault C, Kirisoglu C, Bao G, Arias V, Chan A, Li KK. Adult chronic sleepwalking and its treatment based on polysomnography. Brain. 2005;128:1062-9.

42. Zadra A, Pilon M. NREM Parasomnias. Handb Clin Neurol. 2011;99:851-68.

43. Howell MJ. Parasomnias: an updated review. Neurotherapeutics. 2012;9:753-75

44. Gregory AM, Cousins JC, Forbes EE, Trubnick L, Ryan ND, Axelson DA, et al. Sleep items in the child behaviour checklist: a comparison with sleep diaries, actigraphy, and polysomnography. J Am Acad Child Adolesc Psychiatry. 2011;50:499-507.

45. Mamun AA, O'Callaghan F, Scott J, Heussler H, O'Callaghan M, Najman J, et al. Continuity and discontinuity of trouble sleeping behaviours from early childhood to young adulthood in a large Australian community-based-birth cohort study. Sleep Med. 2012;13:1301-6.

46. Horwood LJ, Fergusson DM, Hayatbakhsh MR, Najman JM, Coffey C, Patton GC, et al. Cannabis use and educational achievement: findings from three Australasian cohort studies. Drug Alcohol Depend. 2010;110:247-53.

Ready to submit your research? Choose BMC and benefit from:

- fast, convenient online submission

- thorough peer review by experienced researchers in your field

- rapid publication on acceptance

- support for research data, including large and complex data types

- gold Open Access which fosters wider collaboration and increased citations

- maximum visibility for your research: over $100 \mathrm{M}$ website views per year

At $\mathrm{BMC}$, research is always in progress.

Learn more biomedcentral.com/submissions 